\title{
A INSTITUIÇÃO ASILAR E SEUS FAZERES COTIDIANOS: um estudo de caso ${ }^{1}$
}

\author{
Maria Amélia Ximenes* \\ Beltrina Corte** \\ Não mais querer, não mais estimar e não mais criar! \\ Ai!, que esse grande cansaço fique sempre longe de mim! \\ Nietzsche, "Assim falava Zaratustra"
}

\section{Resumo}

Este artigo fala sobre instituição, seu cotidiano e a "ociosidade" de seus velhos. Foi elaborado a partir do estudo dessas compreensões, partindo da realidade da vida cotidiana asilar, ao verificar de que maneira esta pode interferir no fazer dos residentes. As respostas identificaram os empecilhos que entravam o trabalho com atividades nessas instituições, empurrando os residentes ao não fazer, a uma "ociosidade" aparente. Um (re)pensar sobre o idoso asilado e o seu fazer.

Palavras-chave: Instituição asilar. Fazer. Cotidiano.

\section{Introdução}

Cresce a cada ano o número de idosos, nos dizem os últimos números do IBGE (2002). Somados a este crescimento, novos desafios surgem decorrentes de questões sociais, políticas e de saúde próprias do envelhecer. Essa nova realidade nos traz à tona questões como a moradia e o cuidado e, dentro desse contexto, a institucionalização do idoso é a mais polêmica e complexa, por envolver considerações polí-

\footnotetext{
Parte da Dissertação de Mestrado em Gerontologia Social, PUC-SP (2005). Apresenta grande similaridade com o artigo O Fazer Institucionalizado: o cotidiano do asilamento, publicado na Revista Kairós Gerontologia, São Paulo v. 9, n. 2, p. 135-145, 2006.

Terapeuta Ocupacional, Especialista em Psicologia da Saúde (UNESP/BAURU), Mestre em Gerontologia Social (PUC/SP), docente do Curso de graduação em Terapia Ocupacional da USC/BAURU, doutoranda do Programa de Estudos Pós Graduados em Ciências Sociais (PUC/SP).

E-mail: maria.amelia.lima@itelefonica.com.br

** Jornalista, Doutora em Ciências da Comunicação (ECA/USP). Docente do Programa de Estudos PósGraduados em Gerontologia (PUC/SP). Coordenadora executiva do web site Portal do Envelhecimento e editora da Revista Kairós Gerontologia, São Paulo. E-mail: beltrina@uol.com.br
} 
ticas, sociais, econômicas, de saúde e psicoemocionais, além de cunho preconceituoso e moral.

\subsection{As Instituições para Velhos}

Não existem dados oficiais atuais a respeito do número de instituições para idosos nem quantos idosos vivem nelas no Brasil. Mendonça (2006) explica que isso se deve a dificuldade no trato do tema, mas já está sendo feito um diagnóstico. A Secretaria Especial dos Direitos Humanos firmou convênio com o Instituto de Pesquisa Econômica Aplicada - IPEA para realização de uma pesquisa que busca o número de instituições e as condições de vida de seus residentes nas diferentes regiões do país.

Camarano (2004) coloca que aproximadamente 107 mil idosos, vivem em instituições, representando $1 \%$ da população idosa. Porém esses números foram inferidos com base no censo demográfico de 2000, a partir do número dos idosos que moravam em domicílios coletivos num total de 113 mil e, destes, 6,1 mil vivem em conventos, hotéis, seminários. Dados que representam certa fragilidade.

Born e Boechat (2002) lamentam a não existência de estudos a respeito, para que se possa fazer uma prospectiva sobre a demanda futura. De qualquer maneira, sabe-se que nos últimos 15 a 20 anos, têm se multiplicado as casas de repouso ou clínicas geriátricas, de caráter privado, com fins lucrativos, principalmente no Sudeste e Sul do país. É fato que a cada ano, mais e mais idosos necessitam desse tipo de serviço.

Conforme Rezende (2004), no Brasil e países de língua portuguesa, as instituições destinadas a abrigarem pessoas idosas, necessitadas de lugar para morar, alimento e cuidado por período integral, são conhecidas por asilos ou albergues. O que se percebe é que a palavra asilo lembra pobreza e rejeição, contém uma carga negativa, sendo geralmente empregada, quando nos referimos a uma instituição destinada a idosos carentes.

A maioria dessas instituições é filantrópica, tem visão caritativa, são geralmente mantidas por associações religiosas (espíritas, católicas, evangélicas), por associações de imigrantes e seus dependentes ou outras organizações beneficentes. Sem infra-estrutura adequada e sem 
profissionais qualificados para atender os residentes, são instituições privadas, algumas clandestinas, oferecendo mínimas condições de tratamento se constituindo, dessa forma em verdadeiros depósitos de velhos (MENDONÇA, 2006).

Este legado pode ser explicado quando nos remetemos a Idade Média, à descoberta do hospital, um lugar essencialmente de assistência aos pobres. As pessoas que prestavam esse serviço assistencial eram caritativas (religiosos ou leigos), que com esse serviço buscavam a salvação da alma, tanto do pobre como a sua, além da função de separação dos indivíduos, que de alguma forma, traziam ameaças à saúde da população. Um lugar de assistência, formação espiritual e exclusão social (FOUCAULT, 2003). Características ainda presentes em algumas instituições brasileiras.

Goffman (2001, p. 11) refere-se a este tipo de instituição como "instituição total" e a define como "um local de residência e trabalho onde um grande número de indivíduos com situação semelhante, separados da sociedade mais ampla por considerável período de tempo, levam uma vida fechada e formalmente administrada". Estas podem ser enumeradas em cinco categorias, uma das quais foi criada para cuidar de pessoas incapazes e consideradas inofensivas como os cegos, os órfãos, indigentes e os velhos. Nesses aspectos, consideram-se as instituições para idosos, local de segregação, de incapazes, de pobreza e abandono, muitas vezes, o retrato da velhice institucionalizada em nossos dias.

Born e Boechat (2002) concordam que falar de idoso institucionalizado é fazer referências a imagens negativas (relacionadas à tristeza e ao abandono) associadas a entidades que o abrigam, para os quais a denominação "asilo" continua em uso ou se encontra atenuada na expressão "instituição asilar". 2

Na verdade a criação dos asilos foi uma necessidade da época (indispensável ainda em nossos dias) na tentativa de solucionar a problemática das doenças, da pobreza e mendicância. Com o passar dos tempos, essas categorias (pobres, mendigos, doentes, loucos, crian-

\footnotetext{
2 A palavra "asylums" foi utilizada, inicialmente, pelos americanos para designar todas as instituições surgidas em alguns países, no início do século XIX. Instituições do tipo pedagógico, como escolas, orfanatos e centro de formação; correcionais, como a prisão, casa de recuperação e casa de correção e instituições ao mesmo tempo correcionais e terapêuticas, como o hospital e o hospital psiquiátrico (FOUCAULT, 1991, p. 89).
} 
ças) foram trabalhadas de modo isolado. Dessa forma surgiram espaços separados: os hospitais, os leprosários, os manicômios, os sanatórios, orfanatos e os asilos que passam a abrigar somente aqueles que não se enquadravam nas outras instituições, como pobres, mendigos, vagabundos e velhos. Somente no século XX, o termo asilo passou a ser uma instituição para velhos. Justifica-se, desse modo na sua origem, as instituições para velhos como um lugar de tristeza, abandono, pobreza e decadência.

\subsection{As Definições de Asilo}

A Política Nacional do Idoso ${ }^{3}$ (BRASIL, 1994) entende asilo como o atendimento em regime de internato ao idoso, sem vínculo familiar ou sem condições de prover a própria subsistência, de modo a satisfazer as suas necessidades de moradia, alimentação, saúde e convivência social. Declara ainda que tal atendimento somente deve ocorrer no caso da inexistência do grupo familiar, abandono, carência de recursos financeiros próprios ou da própria família, sem considerar quaisquer outras condições, seja em caráter temporário seja permanente.

A Portaria 810/89, do Ministério da Saúde (BRASIL, 1989), considera instituições específicas para idosos, os estabelecimentos com denominações diversas e lugar físico equipado para atender pessoas, a partir de 60 anos de idade, com um quadro de funcionários e capacidade para atender as necessidades da vida institucional como um todo, por um período indeterminado, sob regime de internato ou não, pagas ou não.

A Sociedade Brasileira de Geriatria e Gerontologia (SBGG) adotou a expressão "Instituições de Longa Permanência para Idosos" (ILPI) o correspondente a Long Term Care Institution, para designar esse tipo de instituição. Define como "estabelecimentos para atendimento integral institucional, cujo público alvo são pessoas de 60 anos e mais, dependentes ou independentes, que não dispõem de condições para permanecer com a família ou em seu domicílio" (SOCIEDADE . .., 2002-2003, p. 3).

${ }^{3}$ Artigo $3^{\circ}$, regulamentada pelo Decreto $n^{\circ} 1.948$, de 03 de julho de 1996. (BRASIL, 1996). 
A Resolução da Diretoria Colegiada - RDC/ANVISA n ${ }^{\circ} 283$, de 26 de setembro de $2005^{4}$, em seu Art. $1^{\circ}$, aprova o Regulamento Técnico que define normas de funcionamento para as Instituições de Longa Permanência para Idosos, de caráter residencial, define ILPI como "instituições governamentais e não governamentais, de caráter residencial, destinadas a domicílio coletivo de pessoas com idade igual ou superior a 60 anos, com ou sem suporte familiar, em condições de liberdade, dignidade e cidadania". (BRASIL, 2005) ${ }^{5}$

Born (2001) esclarece que independente de qual for a denominação estabelecida, há uma rejeição da sociedade brasileira a instituições que prestam assistência ao idoso (embora não se negue sua importância). Para que isso possa vir a se modificar, seria necessário que essas instituições passassem por um grande processo de reestruturação, para que pudessem cumprir, de maneira satisfatória, suas responsabilidades implícitas perante esses idosos. Essas responsabilidades seriam de proporcionar um lar, um lugar de vida, de aconchego, de identidade e, ao mesmo tempo, de cuidados.

\subsection{O Velho Asilado}

Sabe-se que a grande maioria das instituições não está preparada para proporcionar aos seus residentes, serviços individualizados que respeitem a personalidade, privacidade e modos de vida diversificados. Há uma desvalorização das necessidades do idoso, por se acreditar que estas se limitam a certas prioridades fisiológicas (alimentação, vestuário, moradia, cuidados de saúde e higiene) remetendo ao esquecimento as de nível social, afetivo e sexual (PIMENTEL, 2001).

Pimentel justifica seu pensamento, explicando que ao longo de nossa vida, criamos hábitos, adaptamos e transformamos o nosso espaço, possuímos nossos objetos pessoais e construímos uma rede de relações. A nossa história é construída, a partir de todas essas construções simbólicas e, caso haja uma perda total ou parcial delas, para os idosos representa um corte com o seu mundo de relações e com sua história. Portanto, o idoso tem dificuldade em assumir aspectos da sua vivência, enquanto pessoa plena, isolando-se afetiva e socialmente, negando ou

${ }^{4}$ Considerando esta Resolução, o Ministério da Saúde editou a Portaria n ${ }^{\circ}$ 1868/GM de 11 de outubro de 2005 revogando a Portaria no 810/89, conforme MENDONÇA, 2006, p. 185.

${ }^{5}$ Documento eletrônico. 
desvalorizando as suas capacidades.

$\mathrm{Na}$ verdade, eles não se sentem partes integrantes do espaço onde vivem, não se sentem "pertencer", contrariando o sentimento de comunidade, ficando claro que o asilo não apresenta condições de vida comunitária para os seus residentes; vivem num mundo à parte, onde perdem sua individualidade, entram aos poucos num processo de isolamento e deixam de "existir". Negam-se as possibilidades de elaboração de projetos, por viverem num mundo sem significado pessoal.

Goffman (2001, p. 23) coloca que os internos chegam à instituição com uma "cultura aparente", derivada de um "mundo da família", parte de um esquema amplo - um conjunto de experiência que confirmava uma concepção tolerável do eu e permitia um conjunto de formas de defesa, exercidas de acordo com sua vontade, para enfrentar conflitos, dúvidas e fracassos. Com o tempo ocorre uma mudança cultural no que se refere ao afastamento de algumas oportunidades de comportamento e ao fracasso para acompanhar as mudanças sociais recentes no mundo externo. Dessa forma acaba perdendo alguns papéis em virtude da barreira que o separa do mundo externo.

Esses fatos se comprovam no cotidiano da realidade asilar, por serem comuns da maioria dos idosos, falas que se repetem numa rotina, como se a expressão por palavras, de modo exaustivo, ocasionasse a realização de um desejo, tornando-o uma verdade: "[ . . . ] vou ficar aqui por pouco tempo, logo, logo, meu filho me busca", "Logo que ficar bom da saúde [ . . . ]", "vou voltar para casa, se Deus quiser", "[ . . . ] estou esperando minha filha, daqui a pouco ela chega para me levar de volta para casa".

A idéia de pertencimento, o sentimento de "pertencer" ao grupo em que vive, é o que fundamenta a relação social, portanto, a existência de comunidade torna-se necessária, porque permite um espaço onde os indivíduos possam estabelecer relações de maior proximidade, de intimidade, relações mais pessoais, como explica Mercadante (2002) positivas à vida cotidiana asilar. É importante que o indivíduo se sinta pertencendo, pois é primordial "sentir-se gente entre os pares" (SAWAIA, 1995, p. 23).

Os residentes constroem uma imagem interna que influencia as suas práticas e condiciona a sua maneira de ser. Em certos casos, sentem que há uma imagem tão desvalorizante, que se conformam e agem 
de acordo com ela, uma vez que não lhes é dada a possibilidade de demonstrar que esta é infundada ou distorcida. Além disso, o idoso é estigmatizado e acaba por interiorizar e aceitar a marca que os outros lhe atribuem. Esses aspectos não estão evidentes na instituição, passando desapercebido aos olhos rotineiros dos funcionários e técnicos, mas caracterizam o comportamento de alguns idosos (DRULHE, $1981^{6}$ apud PIMENTEL, 2001)

Endo (2002, p. 43)7 explica que "o nosso eu é um feixe de representações"; durante a nossa vida, nós retemos informações (vindas de diferentes ambientes, lugares, pessoas) sobre nós mesmos, que assumimos como nossas e acreditamos nelas. O que existe de fato é um atravessamento dessas informações, de tal modo que colidem, avizinhamse e alteram-se e que, em dado momento, algumas delas são retidas, e é a partir dessa retenção, que nos permitimos dizer para o outro o que somos. É esta a idéia de feixe, porque o eu não é uma representação específica, nem uma verdade específica, mas revela um caráter transitório, modificando-se, com freqüência, em conformidade com a experiência vivida e dependente de muitos fatores. Portanto, assumindo um caráter de verdade, em um determinado momento vivido.

Moragas (1997, p. 239) $)^{8}$ acredita em uma "morte social", em decorrência de um processo de internação em uma instituição, já que esta, muitas vezes, restringe os contatos sociais dos residentes com o exterior e rompe os seus laços sociais habituais. É identificada como uma perda do papel ativo e econômico e a passagem para um papel passivo, tanto econômico como também social. Além da institucionalização, o autor explica que existem outras manifestações de morte social do idoso, como aposentadoria, mudança de habitação ou bairro, ruptura de laços sociais habituais e prisão.

Retomando o pensamento de Pimentel (2001) fica claro que há um conformismo, semelhante a uma relação de dependência do idoso

\footnotetext{
${ }^{6}$ DRULHE, M. Vivre ou Survivre? Les Centres d'Hébergement pour Personnes Âgées. Paris: Éditions du Centre National de la Recherche Scientifique, 1981. Apud PIMENTEL, 2001.

7 Segundo o autor essa modificação pode ser dada por uma experiência específica, por um acidente que acontece, por um processo de análise, por um livro que se lê, etc. Enfim, essa "verdade" dialoga permanentemente com o que não sou, com o não eu assumindo um caráter de verdade e que assumo como minhas (ENDO, 2002, p. 43).

8 O autor explica que esta se dá pela menor adaptabilidade do idoso à mudança de ambiente, razão pela qual os gerontólogos recomendam que este seja mantido de preferência em seu ambiente costumeiro (MORAGAS, 1997, p. 239).
} 
residente para com a instituição e isso ajuda a compreender a resistência de alguns idosos em participar da vida institucional. Mesmo se dando espaço para que se desenvolvam seus interesses, existem casos em que estes utilizem estratégias de fuga. $O$ grau de participação nas atividades propostas é variável, já que é comum a atitude de alguns idosos de adotarem uma posição de total passividade, traduzindo-se por sentimentos de impotência, incapacidade, inutilidade e, por vezes, o desejo de morrer. Dificilmente, têm uma iniciativa voluntária, pois não se sentem responsáveis pelo bom funcionamento da instituição.

Na realidade cotidiana asilar, a sensação que se tem é de um lugar onde o tempo estagnou. As horas preguiçosas estendem-se, resistem e, no seu marasmo, contaminam todo o ambiente, num quase nada acontecer em suas diferentes horas: idosos sentados estáticos, muitas vezes, um ao lado do outro, sem conversas ou, quando se ouve alguma voz, na maioria das vezes é solitária. Idosos conversam, mas não se ouvem. Uns gritam, sem motivo aparente, outros vagam. A sensação é de desistência da vida. Permanece um tempo vazio de "espera" da morte. Uma "história", uma tática, um conto triste - um tipo de lamentação e defesa - como explica Goffman (2001, p. 64), uma forma de explicar a baixa posição do internado no presente, levando-o ao excesso de piedade por si mesmo, junto ao intenso sentimento, de que, o tempo passado na instituição é perdido, destruído ou tirado da vida da pessoa e precisa ser "cumprido", "preenchido" ou "arrastado" de alguma forma.

Esse tempo chamado de "morto" é o que provavelmente explica as chamadas atividades de distração, aquelas intencionalmente desprovidas de seriedade, com o intuito de fazer o internado esquecer momentaneamente a sua situação real (GOFFMAN, 2001). Atividades sem considerar as necessidades e interesses do internado, ditas por Goffman (2001, p. 65) como "[ . . . ] atividades que torturam o tempo e o matam misericordiosamente." Qual pontuação de início e fim da citação? OK! As necessidades do indivíduo tanto estão relacionadas às questões básicas e concretas da existência (alimentação, moradia, educação, saúde, transporte, trabalho, lazer, segurança) quanto à subjetividade inerente ao homem (gosto pela vida, a percepção de seu bem-estar e prazer, a satisfação e o envolvimento emocional com pessoas e atividades, o propósito de vida e felicidade); como também com a sua participação social, as oportunidades de trabalho significativo e a realização de ta- 
lentos e habilidades pessoais. Todas essas questões diretamente ligadas às execuções dos fazeres cotidianos.

A atividade ou fazer humano 9 é essencial ao equilíbrio físico, psicoemocional e social do idoso, na medida em que favorece o continuar vivendo, mesmo que fatos negativos possam interpor-se ao processo de envelhecimento. Estimula-o a continuar a fazer planos, estabelece os contatos sociais, tornando-o ativo, participante de sua comunidade, autônomo, aos olhos da sociedade, um velho sem o estigma de velho. Inúmeros autores relatam os efeitos benéficos das atividades nas suas diversidades, sejam elas físicas, de lazer, de trabalho, artísticas, sociais, etc. Pois viver, requer movimento, ação, execução, fazer. A linguagem dessa ação, fazer é um dos modos deste conhecer-se, conhecer o outro, o mundo, o espaço, o tempo em que vive e sua cultura. Essa experiência é organizada em estruturas definidas, cujas bases é fundamentada na sua realidade social e no seu relacionamento com o material (que utiliza para tal) e tudo o que o envolve. Por fim, essa ação dá forma e estrutura ao fazer dos sujeitos, estabelecendo um sistema de relações, que colabora para a construção de uma vida cotidiana com qualidade. Castro, Lima e Brunello (2001) ao falarem da qualidade de vida cotidiana, referem-se à transformação concreta da realidade, através dos fazeres diários, como as atividades de autocuidado e manutenção da vida que, visando satisfazer às exigências e necessidades do indivíduo, podem ser pensadas como de consistência vital, no cotidiano de qualquer pessoa.

Esses fazeres diários auxiliam no trabalho de organização e cuidado do cotidiano, chegando a representar a função de estruturação, ao mesmo tempo em que favorecem uma instrumentação técnica dos indivíduos, capacitando-os para a vida, configurando como rede de sustentação para a construção da autonomia e independência, promovendo a convivência e a contextualização do sujeito na cultura e na sociedade (CASTRO; LIMA; BRUNELLO, 2001).

Evidências demonstram que o não fazer é nocivo à saúde do idoso, podendo levá-lo ao declínio de sua capacidade física pelo "desuso" das funções do corpo, atingindo as atividades de vida diária e de vida

\footnotetext{
9 Os fazeres humanos ou atividades humanas são formados por um conjunto de ações que apresentam qualidades, demandam certa capacidade, materialidade e estabelecem mecanismos internos para sua realização. Podem ser desdobradas em etapas, representando um processo na experiência de vida real do sujeito (CASTRO; LIMA; BRUNELLO, 2001).
} 
prática $^{10}$. Conseqüentemente, acaba por levá-lo ao desconhecimento de seu corpo e de si mesmo, expondo-o a uma maior vulnerabilidade às enfermidades. O fazer, portanto, dará suporte para a criação de recursos internos, para que o idoso enfrente o processo de envelhecimento, adaptando-se às mudanças com algum equilíbrio emocional, por fortalecer sua auto-estima, com uma visão de mundo mais positiva, vontade de viver e, por conseguinte, trazendo a esperança de uma vida longeva, com saúde, independência e autonomia.

\section{O Fazer Investigativo}

Considerando as evidências expostas, bem como a necessidade de oferecer contribuições à compreensão dos significados associados à vida cotidiana asilar, privilegiando o fazer do idoso residente, este estudo de caso teve como objetivo, verificar qual é a realidade da vida cotidiana asilar e de que maneira esta pode interferir no fazer dos residentes. Ter como referencial de estudo, a ação e a compreensão científica dos fatos ao mesmo tempo, possibilitou a reflexão de situações, que na realidade pesquisada era tida como óbvia, não se prestando ao estudo, além de poder vivenciar momentos peculiares da cotidianidade asilar, que não estavam à mostra. É só interrogando o que se passa no cotidiano, comenta Pais (2003, p. 28), que nos damos conta de que é nos aspectos frívolos e no "nada de novo" do dia-a-dia, que encontramos condições e possibilidades de resistência que alimentam a sua própria ruptura.

Utilizaram-se como instrumentos de coleta de dados entrevista estruturada com os profissionais e diretoria, observações em campo e relatórios de graduandos do curso de terapia ocupacional. Materiais como documentos institucionais e jornais antigos serviram para dar suporte referencial. Os dados foram categorizados e analisados simultaneamente, conforme foi sendo descrita a história do asilo e seu fazer cotidiano e comparados com a literatura existente, de acordo com os objetivos da pesquisa.

10 Entende-se por atividades de vida diária (AVDs) aquelas que se referem ao autocuidado, como alimentar-se, vestir-se e às de higiene em geral. E as atividades de vida prática (AVPs) às que estão relacionadas às atividades mais complexas, como cozinhar, dirigir, administrar uma casa, lavar roupa, dentre outras. 


\subsection{A Instituição Asilar}

A instituição é localizada numa cidade de porte médio, da região centro-oeste do Estado de São Paulo. Foi fundada no ano de 1940 por uma associação religiosa e nos moldes desse movimento iniciou seus trabalhos acolhendo pobres e mendigos ou qualquer pessoa carente. Em 1976, por haver uma demanda de idosos carentes, sem uma instituição específica que os acolhesse na cidade e, pela maioria dos internos ter mais de 60 anos, a instituição passou a atender somente velhos. ${ }^{11}$ Mantém-se com subvenções do município, contribuições dos membros da associação e da sociedade em geral, por intermédio de campanhas apelativas em diversos locais, de donativos do comércio e indústria, da renda proveniente do serviço de telemarketing, do pagamento dos idosos que recebem algum tipo de benefício ou aposentadoria ${ }^{12}$ e de eventos anuais promocionais.

\subsection{O Local}

A entrada da instituição, o bosque com suas mangueiras e jaqueiras. Bancos frios de cimento e inscrições em vermelho, denunciam o nome de antigos doadores. Os residentes mais independentes os aproveitam para se aquecerem ao sol nas manhãs frias ou, ainda, no verão, gozar da brisa e da sombra das árvores. Feias barracas, nunca desmontadas, o mato e as folhas secas adiante, promovem o sentimento de abandono... esquecimento... e tristeza. Os prédios que abrigam os residentes são chamados de pavilhões e lembram vagões de trem. Arquitetura influenciada pela época de sua fundação? Talvez? Não se sabe. De cor amarela, possuem, cada um, quartos individuais, quartos duplos e triplos. Estes são pequenos com uma janela de madeira, muitas vezes, sem "vitrô" ou quando este existe, é de erguer (a maioria dos residentes não tem forças para abri-lo). Seu mobiliário consta de somente uma cômoda e cama baixa. Somente os residentes que pagam podem

\footnotetext{
${ }^{11}$ É uma entidade civil de direito privado, beneficente, filantrópica, caritativa e de assistência social, sem fins lucrativos. Tem por finalidade a prática da caridade cristã, através da assistência social, abrigando pessoas idosas carentes, assistindo-as na alimentação, saúde, moral e religião. Busca um atendimento integral nas diversas áreas, em regime aberto.

${ }^{12}$ A administração recebe estes benefícios e repassa um percentual de $30 \%$ ao residente beneficiado.
} 
levar objetos como cômoda, televisão ou a cama. No geral, na admissão somente é permitido as roupas. O piso, de cimento vermelho, dá um ar sombrio. Poucos quartos possuem banheiros, obrigando a maioria dos idosos a usar os banheiros coletivos, existentes em cada pavilhão. Todos na cor branca, não possuem adaptações ou tapetes antiderrapantes.

Do lado de fora dos quartos, no lado feminino, um terraço, com bancos, une um pavilhão a outro, com o acesso facilitado por corrimões, feitos com canos de ferro, em toda sua lateral. Do lado masculino, o diferencial é um jardim, em toda a extensão, entre o primeiro e o segundo pavilhão. O grande salão sofreu reformas recentes. Seu acesso foi facilitado por rampas em suas laterais. É o espaço utilizado pelos profissionais e onde as festas são realizadas. Separa os pavilhões femininos dos masculinos. Um lugar onde os residentes têm a seu dispor jogos, como sinucas, mesa para baralho e uma mesa adaptada de bocha. É um lugar freqüentado basicamente pela população masculina e, algumas vezes, temido pela feminina. ${ }^{13}$

Ao fundo do salão, uma grande porta dá acesso ao refeitório, com suas mesas coletivas e bancos de madeira, sem espaldar, e ao minirefeitório (usado somente pelas freiras), com uma mesa e seis cadeiras e depois, a uma grande cozinha. Esses ambientes impressionam o visitante por causarem uma sensação de mal-estar, tristeza e desconforto. A iluminação e ventilação são precárias, móveis inadequados, frias paredes brancas de azulejos e um odor desagradável. Por trás destas construções, está a enfermaria, marcenaria e lavanderia. A marcenaria serve de apoio ao bazar, fazendo pequenos consertos, recuperação e reformas de móveis destinados à venda ou para consumo na instituição. Não há presença de residentes neste serviço. A enfermaria é uma construção antiga como todas as outras, com suas meias paredes pintadas na cor cinza e branca. As duas alas (feminina e masculina) possuem um quarto grande, com dois banheiros pequenos à entrada, com piso em cerâmica vermelha, sem nenhum tipo de adaptação ou presença de tapete antiderrapante no chuveiro. O piso dos quartos é antigo (formado da junção de "pastilhas") da cor cinza, mostra uma certa porosidade, absorvendo líquidos, ocasionando umidade e o odor constante de urina e desinfetante. É o lugar temido por todos os residentes, sendo visto

${ }^{13}$ No salão? Não! É o lugar dos homens. Não é bom ficar lá (D.A.). Fala de uma idosa ao ser convidada a fazer atividades no salão. 
como o lugar que antecede a morte. Concepção também compartilhada pelos funcionários.

\subsection{Quem São seus Residentes}

A instituição tem capacidade para abrigar 80 idosos. ${ }^{14} \mathrm{~A}$ maioria é do sexo masculino, com idades que variam de 50 a 116 anos, documentados oficialmente. Em fevereiro de 2005, a instituição contava com 79 idosos: 35 mulheres e 44 homens. São oriundos do próprio município, da região e até de outros Estados brasileiros. O que chama a atenção é a presença de homens abaixo da faixa etária considerada limite para institucionalização: 60 anos. São indivíduos com histórias de alcoolismos ou doenças intercorrentes, deficiências mentais ou doenças mentais. Foram indicados por outras instituições religiosas ou passaram pela reforma psiquiátrica e por não terem onde ficar, a instituição os acolheu.

Os residentes possuem familiares em sua maioria distantes (tios, primos, sobrinhos) não havendo vínculo afetivo forte. Grande parte é independente ou semidependente. Existe uma minoria em situação de total dependência. A esclerose, principalmente nas mulheres e as doenças cardiovasculares, nos homens, são as patologias mais freqüentes; há um número considerável de amputados (decorrentes de complicações da diabetes) e alguns casos de alcoolismo e doença mental grave.

Como o objetivo da instituição é atender idosos carentes, a média de renda destes é de um salário mínimo; alguns são amparados pela Lei Orgânica da Assistência Social (LOAS), necessitando de auxílio para complementar seus gastos pessoais principalmente com medicamentos. Poucos possuem renda acima de um salário mínimo. Grande parte dos residentes diz que está no asilo por vontade própria: os homens alegam solidão, falta de companheira (por não terem casado, viuvez ou "boemia"15) e por baixa ou falta de aposentadoria; as mulheres relatam que

\footnotetext{
14 A instituição divide as vagas da seguinte maneira: 80 para residentes e 20 para o que eles chamam de centro de convivência, que na realidade é um centro dia (os idosos chegam pela manhã e vão embora às 18 horas, não há relação com os internos). É um trabalho implantado recentemente na instituição e por não fazer parte dos objetivos propostos por esta pesquisa, que aborda somente os internos, não se enquadra neste contexto.

${ }^{15}$ Diz respeito aos residentes que viviam de farras e por esse motivo foram banidos de suas famílias. Falase que esta talvez seja uma das justificativas para a quantidade de residentes homens serem maior do que de mulheres, já que estes estão em grande quantidade.
} 
não querem atrapalhar a vida dos filhos, pois estes são muito ocupa$\operatorname{dos}^{16}$. Os mais novos (50 a 60 anos) queixam-se do desemprego, tanto deles como dos filhos. Alguns residentes têm liberdade para sair, desde que sejam antecipadamente comunicados os horários de saída e de chegada. Segundo a fala da direção, "estas regras foram estabelecidas para controle das saídas, já que alguns idosos dispõem de dinheiro e podem gastá-lo de maneira inconveniente: produtos prejudiciais à sua saúde, como álcool e doces".

\subsection{Dirigentes e Profissionais}

A diretoria é formada por 20 membros $^{17}$, todos da associação religiosa. Porém, quem responde cotidianamente pela vida institucional, é a secretária da diretoria. Conta com uma enfermeira-padrão, uma assistente social, uma nutricionista, uma psicóloga, uma recreadora, dois técnicos em enfermagem, um auxiliar de escritório, um motorista, três cozinheiras, quinze auxiliares gerais e um marceneiro. Todos cumprem contrato de oito horas diárias, num total de quarenta, no período de 8 da manhã às 17 horas. As exceções são dois técnicos em enfermagem e um auxiliar de serviços gerais, que cumprem 12 horas de trabalho, por 36 de descanso. Observou-se que existe uma rotatividade dos profissionais, tanto das áreas técnicas como dos demais serviços, em decorrência de baixos salários. As entrevistas mostram que a maior parte desses profissionais ou é recém-formada, ou estava desempregada por algum tempo, mas que, na primeira oportunidade de melhora profissional, saem da instituição.

Existem profissionais que prestam serviços voluntários, de acordo com suas disponibilidades. São eles: um dentista, um médico, uma manicure e um barbeiro, além de quatro religiosas que residem em uma casa dentro do asilo. Estudantes de Fisioterapia, Terapia Ocupacional, Odontologia, Fonoaudiologia e Educação Física fazem estágios, de acordo com as necessidades de suas Universidades, através de convênios firmados entre o asilo e as Universidades da cidade. Ao indagar sobre experiência profissional, somente um dos profissionais da instituição disse ter feito curso e ter alguma experiência com velhos. O não

${ }^{16}$ Segundo levantamento feito pelos alunos do Curso de Terapia Ocupacional no ano de 2002.

${ }^{17}$ Os membros da diretoria não recebem remuneração por seus cargos. 
conhecimento sobre gerontologia, o despreparo interfere no trabalho, com o fazer dos residentes e, conseqüentemente, no próprio fazer destes, ao ocasionar, muitas vezes, situações deprimentes de desrespeito e desprezo ao trabalho do outro profissional e aos residentes como podem ser observadas nas narrativas a seguir:

É comum durante um atendimento, os alunos serem interrompidos pelo técnico de enfermagem, que sem a menor discrição, chega sem pedir licença, vai distribuindo os comprimidos entre os idosos e dá a ordem, em voz alta: é para engolir! Nem ao menos lhes oferecem um copo com água para que o comprimido seja ingerido. (DIÁRIO DE CAMPO, 2003).

Foi por volta das $10 \mathrm{~h} 30$ de uma manhã de sol de outubro. Estávamos finalizando as atividades do estágio no quarto da dona M., quando ouvimos risadas e aplausos do lado de fora. Era uma profissional da instituição que estava desfilando no espaço entre os pavilhões. Vestia vários vestidos e seu pescoço exibia inúmeros colares. Andava com passos pesados e falava de modo ininteligível. Imitava uma das residentes, dona R., deficiente mental. Os profissionais e funcionários da instituição vibravam, se divertiam... (DIÁRIO DE CAMPO, 2004).

\subsection{A Desorganização dos Fazeres}

A instituição não dispõe de um calendário, especificando os dias e as horas relativas aos trabalhos daqueles não contratados. Cada Universidade escolhe o dia, conforme sua conveniência, como também os voluntários comparecem conforme sua disponibilidade. Isso gera uma "certa disputa" entre eles por espaço, cadeiras, mesas e até pelos residentes. Há uma "invasão" institucional, na qual ninguém se entende, nem mesmo os moradores que se irritam com tantos convites. $\mathrm{O}$ resultado é a frustração geral e os residentes ficam numa situação de disponibilidade freqüente: é só chegar lá e "pegá-los". Muitos fazeres confundem, irritam muitas vezes: “Já disse que não quero ir!!!”. É o 
que mais se ouve. O poder de decisão dos residentes, sua autonomia ${ }^{18}$, não é valorizada. Esse "combate à ociosidade" dos residentes acaba se transformando numa antiterapia, na medida em que a autonomia dos residentes é completamente desrespeitada.

\subsection{A Rotina dos Fazeres Diários}

Às cinco horas da manhã os funcionários de serviços gerais se dividem entre os pavilhões. Começa mais uma jornada de trabalho. É hora do banho e da faxina dos quartos. Alguns idosos reclamam, xingam, outros choram: não querem tomar banho. A frase: "Vamos ver eu não tenho o dia inteiro", é ouvida a cada momento. De repente, se ouve um barulho ensurdecedor... É a sirene, avisando que o café da manhã está pronto. "Ah! A maioria se queixa de problema de surdez", é a justificativa para a altura de volume do som. Alguns residentes se dirigem rápido ao refeitório; outros param com as mãos nos ouvidos. São 7 h30 e, de repente, a lentidão parece não mais existir. Ficam em fila para serem servidos pela funcionária da cozinha e de posse de seu café com leite e pão, sentam nos bancos e comem. Não há conversas. Logo desocupam o lugar, pegam mais pão e vão embora para seus quartos. "É para guardar para a noite, disse uma senhora, sorrindo...". Os residentes que não conseguem ir até o refeitório, esperam seus cafés nos quartos. "Demorou tanto que já está frio, reclama a residente". Servem-se sentados em suas camas, fazendo apoio em suas pernas, não há mesa nos quartos. "A senhora não tem jeito, já derramou café de novo na cama e no chão. Vai dormir molhada", reclama a faxineira.

$\mathrm{Na}$ enfermaria, as faxineiras ainda não terminaram seu serviço. Os cafés esfriam em cima dos criados-mudos. Nas camas, os residentes que não conseguem vestir-se sozinhos, esperam, sem roupa, sua vez; não há pudor. Ao mesmo tempo em que trocam a cama, vestem os velhos. Na mesma rapidez, penteiam os cabelos de todos. Uma reclama; do outro lado, um outro xinga. São quase dez horas, tudo limpo. Alguns cafés foram esquecidos... Após o café, alguns voltam a se deitar, outros tomam sol e a maioria dos homens fica no salão, jogando ou conversando.

${ }^{18}$ Autonomia entendida como exercício da autodeterminação e habilidade de poder atuar livre de interferência de outras pessoas. (HERÉDIA; CORTELLETTI; CASARA, 2004). 
A sirene toca. O alvoroço é geral. São $11 \mathrm{~h}$ 30min; o almoço os espera. O cardápio depende do que foi doado: "Uma vez foi batata durante um mês, de tudo que é jeito." (D. R.). "Ontem teve uma feijoada gostosa! Comi no almoço e na janta." (A.). Da mesma maneira, os mais dependentes recebem seus almoços no quarto, em um pote plástico com tampa. O jantar é a última refeição do dia. A sirene novamente o anuncia às $17 \mathrm{~h} 30 \mathrm{~min}$. Tudo se repete como no almoço. A noite chega. Todos os funcionários já foram embora. Somente três trabalham à noite: o guarda noturno, a auxiliar de enfermagem e um auxiliar de serviços gerais. Um funcionário da noite fala o que ocorre ali em seu período:

O horário de descanso depois do jantar, que tem que ser respeitado e todos devem estar nos seus quartos e não podem sair. Mas como vou fazer pessoas sem sono (porque dormem de tarde) dormirem, permanecer em seus quartos? Há! Eu deixo eles ficarem passeando um pouco, ficarem à vontade até a meianoite. Aí eu insisto para irem pro seus quartos, se não fica difícil controlar a situação. Uns assistem $\mathrm{TV}$, outros vão até a enfermaria bater papo e quando está calor, uns jogam truco. É um horário que eles me procuram para conversar. À noite, é a hora que vem as perguntas: o porquê de estar ali, o porquê a família os colocou ali. As mulheres falam da falta do companheiro. É a hora que a R. junta suas bonecas... A I. aproveita para fumar mais à vontade, sem as pessoas pegarem no seu pé, porque faz cigarros grossos, com papel de embrulho (é o seu prazer). Alguns se penalizam (por estarem lá) e dizem que é o resultado da vida que levaram, por não terem sido uma pessoa boa. (L.).

Este funcionário tem conhecimento básico na área do envelhecimento e isso o torna mais tolerante quanto às regras, permitindo que os velhos fiquem à vontade, se sintam em suas casas e escolham seus $f a$ zeres. O que ele "faz", é na verdade, o que Born (1996) afirma que uma instituição para velhos, deve fazer: combinar liberdade e flexibilidade com limites e restrições. É importante que o residente possa desfrutar de um ambiente descontraído, dedicar-se àquilo que lhe seja prazeroso, 
do seu interesse. A instituição parece reviver a cada noite através de fazeres livres, escolhidos pelos seus residentes. É o momento de reflexão, liberdade e de interação. Quem sabe esse é o momento, no qual se sintam os donos da casa? Talvez, como diz Medeiros (2004), sintam-se num lar, pois descobriram o mistério do conforto. Ele, talvez, é o que revigora, permite suportar, a rotina do fazer institucionalizado.

\section{Fatores que Interferem nos Fazeres Asilares}

Percebe-se que a instituição, como a grande maioria dos asilos, foi criada por uma associação religiosa. Mantém características de sua fundação: a forma de administração (o dirigente tem que pertencer à associação), à busca de recursos (apela para prática da caridade) e uma dosagem de "assistencialismo", camuflada pela diversidade de áreas profissionais. Isso tem interferido no fazer dos residentes, na medida em que estes só são valorizados, quando podem ser transformados em renda. Dessa forma, os fazeres diários dos residentes, os de lazer e outros não são percebidos. Como não são percebidos, não existem, promovendo conferindo? a fama de "ociosos" aos residentes e, conseqüentemente valorizando o ser velho apenas enquanto ser produtivo para o mercado e não como produtor social.

Essa visão, aliada ao assistencialismo é realimentada pelos profissionais e parte da sociedade que rotula o residente asilar como "coitado", incapaz e improdutivo, impedindo que se veja os fazeres escolhidos pelos residentes, enquanto produtores sociais.

A instituição, portanto, não dá importância a outros fazeres, como as atividades de vida diária e de interação entre eles, os visitantes, estagiários, voluntários, dentre outros. Inclusive as atividades religiosas, de lazer como assistir TV, ouvir rádio, jogar baralho, dominó ou sinuca entre outras, passam desapercebidas, em um cotidiano regido pelo horário das refeições, dentro de um consenso falso de "ociosidade" e em um ambiente de provisoriedade. Ambiente que traz aos sentidos a sensação de abandono e tristeza, dando a impressão de marasmo, uma vez que o real fazer institucional é o não investimento na vida. Na realidade, é a espera da morte.

O trabalho voluntário dentro da instituição é feito de modo solitário e estes não recebem qualquer treinamento nem estão integrados 
à equipe e nem tem uma visão sobre o que é o envelhecer. A instituição tem uma equipe de profissionais de diversas áreas; porém, estes não desenvolvem um trabalho integrado. Os residentes nunca são consultados previamente sobre interesses nas atividades propostas. Essas questões da realidade cotidiana asilar levaram a descoberta de oito fatores que interferem no fazer dos residentes:

a) a "espera da morte", a instituição não investe em vida: ausência de projetos que a ressignifique;

b) a falta de formação sobre o processo de envelhecimento humano na perspectiva do ser que envelhece. Essa formação é imprescindível para que os profissionais e dirigentes possam dar qualidade e significado aos fazeres dos residentes;

c) os regulamentos institucionais, por regerem todos os fazeres, impedem a flexibilidade e liberdade, "temperos" saudáveis à vida do residente;

d) a rotatividade profissional é outro fator junto às suas conseqüências: inexperiência profissional; rupturas constantes nos trabalhos, não havendo continuidade destes, resultando na não formação de vínculos; desorganização dos fazeres institucionais por não ser um trabalho integrado entre equipe profissional, funcionários, voluntários, estagiários e dirigentes;

e) a falta de autonomia, por levar ao isolamento, à desvalorização do residente, à improdutividade social, enfim, fazer que não dá sentido à vida;

f) os ambientes e os materiais, considerados essenciais para o fazer. Caminham juntos por relacionarem-se aos quesitos: independência, segurança, risco, limite de desempenho e conforto. Um ambiente calmo, previsível, acolhedor, com cores estimulantes e odores agradáveis são qualidades indispensáveis a um fazer significativo;

g) a ditadura da rotina de horários dos fazeres diários por condicionar os residentes a viverem em função dos mesmos. A rotina paulatinamente os arrasta à despersonalização, à perda da dignidade e do respeito;

h) o sentimento de não-pertencimento. O sentido de pertencer favorece os fazeres porque dá a idéia de fazer parte, trazendo a sensação de segurança, de conhecer com minúcia o espaço, favorecendo a vontade de conservá-lo, o que não é observado na instituição;

i) conhecer estes fatores é ter à mão conceitos essenciais para 
desenvolver um trabalho de excelência, em instituições que abrigam velhos. A "chave" do mistério, "por que os residentes não querem participar de atividades", começa assim a ser desvendado.

\section{O Cotidiano do Asilamento e seus Fazeres}

Os asilos precisam de vida, dinamismo, a partir da energia que venha da vontade do fazer tanto do residente quanto do profissional. Para que isso seja viabilizado, eles têm que investir na qualificação de todos os funcionários em geral, voluntários e diretores, além de certificar-se do gosto de todos pela área. Esse é o primeiro passo para gerar a dedicação e a vontade de fazer melhor, estabelecendo e favorecendo, com isso a participação e interlocução dos residentes, portanto, aumentando as possibilidades de fazer.

Todos os fazeres dentro da instituição, embora muitas vezes, não estejam relacionados, estão interligados de alguma forma e, por isso, um trabalho integrado em equipe com uma proposta de ação que abranja todos os fazeres institucionais deve ser pensada. A equipe deverá estar sintonizada num mesmo objetivo e ciente que colaborar com seus saberes, orientar e formar o voluntariado é essencial. Além disso, a instituição tem que "conhecer" cada residente: ter em mãos uma avaliação individual de suas capacidades, necessidades e interesses. Para, em seguida, conjuntamente, analisar os fazeres a serem desenvolvidos, adequando-os conforme a capacidade, disponibilidade e interesse de cada residente.

Portanto, conhecer quem são seus residentes e ouvi-los quanto à organização dos fazeres e das decisões da vida institucional, são objetivos primordiais a qualquer trabalho numa instituição asilar. Essa informação orienta todo o fazer institucional, porque o residente passa a ser sujeito do seu fazer. O trabalho interventivo nas instituições é infrutífero, na maioria das vezes, pelo não respeito à diversidade do envelhecer. A instituição, ao não ter um projeto de gestão, que leve em conta a ressignificação da vida, o trata com uniformidade. É necessário que se estudem procedimentos lógicos que abranjam a singularidade do residente, sem perder de vista sua socialização. As instituições para idosos precisam tomar conhecimento, se conscientizarem da importância de cada área que trabalha o envelhecimento e vê-las como necessárias 
e importantes.

Enfim, para desenvolver um trabalho sério, a instituição tem que investir na acessibilidade e qualidade dos materiais utilizados, prezando, assim, a segurança de seus residentes. Ambiente seguro garante uma maior independência, exercitando, assim, a autonomia.

O cotidiano promove fazeres que passam desapercebidos dentro da cotidianidade asilar. Daí a necessidade do olhar e do trabalho de uma equipe qualificada para que esses fazeres sejam incorporados dentro do fazer institucional.

O fazer nos acompanha em todos os nossos momentos, faz parte da nossa vida e deveria continuar a nos acompanhar até a morte. Falta que nos conscientizemos disso para que ele venha a ter um valor na velhice.

\title{
RESIDENTIAL HOMES FOR THE ELDERLY AND THEIR DAILY ACTIVITIES: a case study
}

\begin{abstract}
This article talks about residential home for elderly, its daily living and "idleness" among residents. It was produced from the study of these concepts, having the reality of the daily living in institutional context as a starting point to find the ways it can interfere on the activity of the residents. The answers identified the obstacles which hinder the work with activities in these contexts, leading the residents to not doing anything, to an apparent "idleness". It is a rethinking about the elderly residential home resident and their activity level.
\end{abstract}

Keywords: Elderly home. Activity. Daily living.

\section{REFERÊNCIAS}

BORN, T. Cuidado ao Idoso em Instituição. In: NETTO, M.P. Gerontologia: a velhice e o envelhecimento em visão globalizada. São Paulo: Atheneu, 1996. 524p. p.403-414. 
Quem Vai Cuidar de Mim Quando Eu Ficar Velha? Revista Kairós Gerontologia, São Paulo, v. 4, n. 2, p.135-148, 2001.

BORN, T.; BOECHAT, N. S. A Qualidade dos Cuidados ao Idoso Institucionalizado. In: FREITAS, E. V; PY, L.; NERI, A. L.; CANÇADO, F. A. X.; GORZONI, M. L.; ROCHA, S. M. Tratado de Geriatria e Gerontologia. Rio de Janeiro: Guanabara Koogan, 2002. P. 768-777.

BRASIL. Ministério da Saúde. Portaria nº 810, de 22 de setembro de 1989. Aprova normas e os padrões para o funcionamento de casas de repouso, clínicas geriátricas e outras instituições destinadas ao atendimento de idosos, a serem observados em todo o território nacional. Diário Oficial [da] União, Brasília, DF, 27 set. 1989. Seção 1, p. 17.297-17.298. Disponível em: < http://www. mp.ba.gov.br/atuacao/cidadania/geido/legislacao/portaria_810_89.asp $>$. Acesso em: 10 jul. 2005.

BRASIL. Lei no ${ }^{8} 842$, de 04 de janeiro de 1994. Dispõe sobre a Política Nacional do Idoso, cria o Conselho Nacional do Idoso e dá outras providências. Diário Oficial [da] União, Brasília, DF, 05 jan. 1994. Seção 1, p. 77. Disponível em: <http://www.planalto.gov.br/ccivil_03/Leis/L8842.htm>. Acesso em: 10 jul. 2005.

BRASIL. Decreto n ${ }^{\circ} 1.948$, de 03 de julho de 1996. Regulamenta a Lei no 8.842 , de 04 de janeiro de 1994, que dispõe sobre a Política Nacional do Idoso, e dá outras providências. Diário Oficial [da] União, Brasília, DF, 03 jul. 1996. Seção 1, p. 12277. Disponível em: <http://www.cressdf.org.br/2006/6/22/Pagina40. htm>. Acesso em: 10 jul. 2005.

BRASIL. Agência Nacional de Vigilância Sanitária. Resolução RDC n ${ }^{\circ}$ 283, de 26 de setembro de 2005. Aprova o Regulamento Técnico que define normas de funcionamento para as Instituições de Longa Permanência para Idosos. Diário Oficial [da] União, Brasília, DF, 27 set. 2005. Seção 1, p. 58-60. Disponível em: $<$ http://www.saude.mg.gov.br/atos_normativos/legislacao-sanitaria/estabelecimentos-de-saude/atencao-ao-idoso/RES_283.pdf $>$. Acesso em: 09 jun. 2007.

CAMARANO, A. A. (Org.). Os Novos Idosos Brasileiros: muito além dos 60. 
Rio de Janeiro: IPEA, 2004.

CASTRO, E. D.; LIMA, E. M. F. A.; BRUNELLO, M. I. B. Atividades Humanas e Terapia Ocupacional. In: DE CARLO, M. M. R. P.; BARTALOTTI, C. C. Terapia Ocupacional no Brasil: fundamentos e perspectivas. São Paulo: Plexus, 2001. P. 41-59.

ENDO, P. Sujeito Histórico, Sujeito Psíquico. Revista Kairós Gerontologia, São Paulo, Caderno Temático 2, p. 39-56, 2002.

FOUCAULT, M. A Verdade e as Formas Jurídicas. 4.ed. Rio de Janeiro: PUC/ Departamento de Letras: NAU, 1991. . Microfisica do Poder. 18.ed. São Paulo: Graal, 2003.

GOFFMAN, E. Manicômios, Prisões e Conventos. 7.ed. São Paulo: Perspectiva, 2001.

HERÉDIA, V. B. M.; CORTELLETTI, I. A.; CASARA, M. B. Institucionalização do Idoso: identidade e realidade. In: CORTELLETTI, I. A.; CASARA, M. B.; HERÉDIA, V. B. M. Idoso Asilado: um estudo gerontológico. Caxias do Sul: Educs/Edipucrs, 2004. P. 13-60.

IBGE. Perfil dos Idosos Responsáveis pelos Domicílios no Brasil: 2000. Estudos e Pesquisas: informação demográfica e socioeconômica, Rio de Janeiro, n. 9, 2002. Disponível em: $<$ http://www.ibge.gov.br/home/estatistica/populacao/perfilidoso/perfidosos2000.pdf.> Acesso em: 26 ago. 2007.

MEDEIROS, S. A. R. O Lugar do Velho no Contexto Familiar. In: PY, L.; PACHECO, J. L; SÁ, J. L. M.; GOLDMAN, S. N. Tempo de Envelhecer: percursos e dimensões psicossociais. Rio de Janeiro: NAU, 2004. P. 185-192.

MENDONÇA, J. M. B. Instituição de Longa Permanência pra Idosos e Políticas Públicas. Revista Kairós Gerontologia, São Paulo, v. 9, n. 2, p.168-190, 2006.

MERCADANTE, E. F. Comunidade como um Novo Arranjo Social. Revista 
Kairós Gerontologia, São Paulo, v. 5, n.2, p.17-34, 2002.

MORAGAS, R. M. Gerontologia Social: envelhecimento e qualidade de vida. São Paulo: Paulinas, 1997.

PAIS, J. M. Vida Cotidiana, Enigmas e Revelações. São Paulo: Cortez, 2003.

PIMENTEL, L. M. G. O Lugar do Idoso na Família: contextos e trajetórias. Coimbra: Quarteto, 2001.

REZENDE, J. M. Linguagem Médica: "institucionalização" do idoso. Disponível em: <http://www.usuarios.cultura.com.br/jmrezende>. Acesso em: 19 mar. 2004.

SAWAIA, B. B. O Calor do Lugar: segregação urbana e identidade. São Paulo em Perspectiva, São Paulo, v. 91, n. 2, abr./jun., 1995.

SOCIEDADE BRASILEIRA DE GERIATRIA E GERONTOLOGIA. Manual de Funcionamento para Instituição de Longa Permanência para Idosos. São Paulo, 2003.

Recebido em: 19.12.2006

$1^{a}$ reformulação: 18.05.2007

$2^{a}$ reformulação: 13.06.2007

Aceite final: 03.07.2007 